\title{
Molecular characteristics of mismatch repair genes in sporadic colorectal tumors in Czech patients
}

Veronika Polakova Vymetalkova ${ }^{1,2^{*}}$, Jana Slyskova ${ }^{1,2}$, Vlasta Korenkova ${ }^{3}$, Ludovit Bielik ${ }^{1,2,4}$, Lucie Langerova ${ }^{3}$, Pavel Prochazka ${ }^{1,2}$, Alexandra Rejhova ${ }^{1}$, Lucie Schwarzova ${ }^{2}$, Barbara Pardini ${ }^{5}$, Alessio Naccarati ${ }^{1,5}$ and Pavel Vodicka ${ }^{1,2^{*}}$

\begin{abstract}
Background: Mismatch repair (MMR) genes are known to be frequently altered in colorectal cancer (CRC). Both genetics and epigenetics modifications seems to be relevant in this phenomenon, however it is still not clear how these two aspects are interconnected. The present study aimed at characterizing of epigenetic and gene expression profiles of MMR genes in sporadic CRC patients from the Czech Republic, a country with one of the highest incidences of this cancer all over Europe.

Methods: Expression levels and CpG promoter methylation status of all MMR genes were evaluated in DNA from tumor and adjacent mucosal samples of 53 incident CRC patients.

Results: We have found significantly increased transcription levels in EXO1 gene in tumor tissues $(P=0.05)$ and significant over-expression of MSH3 gene in colon tumors when compared to adjacent mucosal tissues $(P=0.02)$. Interestingly, almost all MMR genes were differently expressed when localization of tumors was compared. In particular, colon tumors showed an up-regulation of EXO1, MSH2, MSH3, MSH6, and PMS2 genes in comparison to rectal tumors $(P=0.02)$. Expression levels of all MMR genes positively correlated between each other. The promoter methylation of MLH1 gene was observed in 9\% of CRC tissues only.
\end{abstract}

Conclusions: In our study, we have observed different pattern of MMR genes expression according to tumor localization. However, a lack of association between methylation in MMR genes and their corresponding expressions was noticed in this study, the relationship between these two aspects is worthy to be analyzed in larger population studies and in pre-malignant stages.

Keywords: Colorectal cancer, Mismatch repair genes, Expression levels, Promoter methylation

\section{Background}

Colorectal cancer (CRC) represents a serious health problem in the Central Europe and particularly in the Czech Republic, where the incidence for colon and rectal cancers ranks the third and the first highest worldwide, respectively [1,2]. Notably, rates among males in the Czech Republic and Japan have already exceeded the peak of incidence observed in the United States, Canada,

\footnotetext{
* Correspondence: vpolakova@biomed.cas.cz; pvodicka@biomed.cas.cz ${ }^{1}$ Institute of Experimental Medicine Academy of Sciences of the Czech Republic, Prague, Czech Republic

${ }^{2}$ Institute of Biology and Medical Genetics, First Faculty of Medicine Charles University, Prague, Czech Republic

Full list of author information is available at the end of the article
}

and Australia, where rates are declining or stabilizing $[3,4]$. The reasons for such frequencies are unknown. It is generally accepted that the etiology of CRC is multifactorial, involving hereditary and environmental factors, as well as somatic changes occurring during tumor progression [5].

There are at least three distinct, and relatively discrete, molecular pathways associated with this disease: chromosomal instability (CIN), microsatellite instability (MSI) and the cytosine phosphate guanine $(\mathrm{CpG})$ island methylator phenotype (CIMP). The development of MSI pathway (15\% of CRC) is considered to be due to defective DNA mismatch repair (MMR) system [6]. In CIMP, a number of

\section{Biomed Central}


genes become transcriptionally silenced due to hypermethylation of their promoters, and this represents a key epigenetic mechanism of inactivation of tumor suppressor genes [7], as well as MMR genes. Impaired MMR system, arising frequently from aberrant methylation of gene promoters, may be detectable by an altered gene and protein expression patterns. Aberrant DNA methylation - hypermethylation and hypomethylation compared to normal tissue - has been associated with a large number of human malignancies, including CRC [8]. DNA hypomethylation, prevalent as a genome-wide event, usually occurs in more advanced stages of tumor development whereas DNA hypermethylation is often observed as a discrete, targeted event within tumor cells, resulting in specific loss of gene expression [9].

Based on a number of relatively large case-control and prospective cohort studies, $\sim 30-40 \%$ of sporadic proximalsite colon cancers are CIMP positive, compared to $3-12 \%$ of distal colon and rectal cancers [10,11]. Thus, CIMP is attributable to tumors of the proximal colon, independently of MSI status. CIMP has been also associated with BRAF mutations in both microsatellite stable and unstable colon cancers $[11,12]$. It has been suggested that there are two general types of CIMP in sporadic tumors: CIMP high, related to BRAF mutations and MLH1 methylation, and CIMP low, related to KRAS mutations [13].

Approximately $90 \%$ of all MMR alterations/modifications in sporadic CRC cases are most commonly caused by epigenetic inactivation of $M L H 1$ or $M S H 2$ gene [14]. The hypermethylation of the $M L H 1$ promoter is also the predominant cause of MSI high (MSI-H) in sporadic tumors [15]. MSI-H cancers with methylated $M L H 1$ are distinct from the rest of CRC by delayed onset and association with the female gender [16]. On the other hand, CRC cases without altered MMR genes show low-frequency MSI (MSI-L) or are microsatellite stable (MSS) [14]. Moreover, gene alterations of other MMR genes may also be involved in the CRC progression [17]. Goel et al. [18] assumed that germline hypermethylation of $M L H 1$ and $M S H 2$ may serve as predisposing events in some CRC cases.

The Czech Republic has one of the highest reported incidences of CRC worldwide, thus the analysis of mRNA expression profile of MMR genes and their epigenetic characterization has a great meaning. Apparently, the clarification of a potentially abnormal epigenetic profile of tumor tissues, as well as their genetic constitution, could contribute to better classify the CRC cases or could ultimately result in the improvement of therapy.

Thus the aim of our study was to investigate the epigenetic characteristics and gene expression profiling of MMR genes in tumors of CRC patients of Czech nationality, with respect to their clinical and histopathological characteristics. We have hypothesized that the high incidence of CRC in this country could be due to different genetic and epigenetic pattern of DNA repair genes, which could reflect possible specific geographical, ethnic, dietary or lifestyle factors.

\section{Methods \\ Patients' characteristics and collection of biological specimen}

Fifty three patients with sporadic CRC were recruited between 2009 and 2011 at the Thomayer Hospital and at the General University Hospital (both located in Prague, Czech Republic), where they underwent surgical resection. All patients signed an informed consent. Ethics approval was granted by the committees of the above hospitals.

From each patient, tumor tissue and adjacent mucosal colon/rectal tissue (5-10 cm distant from the tumor) were resected and deep frozen immediately after removal. Peripheral blood was taken a day before surgery and stored at $4^{\circ} \mathrm{C}$ until processing that was no longer than 3 hours. The clinical stage of patients at diagnosis was classified according to the tumor-node-metastasis (TNM) system according to UICC (Union for International Cancer Control).

Tumor and adjacent mucosal tissues were homogenized by MagNA Lyser (Hoffmann-La Roche). Genomic DNA and mRNA were isolated from tumor tissues and adjacent mucosal tissue with AllPrep DNA/RNA Isolation Kit protocol according to the manufacturer's instructions (Qiagen, Hilden, Germany).

\section{MSI status}

MSI was assessed by multiplex PCR with pseudomonomorphic mononucleotide markers BAT-25, BAT-26, NR21, NR-24, NR-27 using primers labeled with FAM, HEX, or NED followed by analysis of PCR products on $5 \%$ denaturing gel electrophoresis on ABI PRISM 310 System (Applied Biosystems) as described previously by [19].

Tumor DNA samples were compared, and tumors showing instability at one or two locus were scored as MSI-low (MSI-L), at three or more loci as MSI-high (MSI-H). Genescan software was used for calculation of the size of each fluorescent PCR product.

\section{Gene expression profiling \\ Gene selection}

A panel of all MMR genes was extracted from the complete list of all DNA repair genes organized by pathways available online (http://sciencepark.mdanderson. org/labs/wood/DNA_Repair_Genes.html\#MMR). Eleven genes (EXO1, MLH1, MLH3, MSH2, MSH3, MSH4, MSH5, MSH6, PMS1, PMS2, and PMS2L3) were analyzed for mRNA expression levels.

\section{Sample preparation}

The total RNA was measured on ASP-3700 UV/Vis Spectrophotometer (Avans-Biotechnology, Taiwan) for 
quantity control and $\mathrm{OD}_{260 / 280}$ ratio for an indication of nucleic acid purity. RNA integrity number (RIN) was checked using Agilent Bioanalyzer 2100, with RNA 6000 Nano Assay (Agilent Technologies). Each pair of tumor/adjacent mucosal tissue did not differ by more than \pm 2 RIN units. The complementary DNA (cDNA) was obtained from $1 \mu \mathrm{g}$ of total RNA by using First strand cDNA synthesis kit (MBI Fermentas, Vilnius, Lithuania). All samples were tested to exclude possible inhibition of the quantitative PCR (qPCR) reaction by spiking with RNA from an extraction control kit (TATAA, Sweden). cDNA was diluted to $10 \mathrm{ng} / \mathrm{mL}$ and preamplified for 18 cycles on a Bio-Rad CFX96 Real Time PCR Instrument (Bio-Rad) with TaqMan Preamp Master Mix (Applied Biosystems) according to the manufacturer's protocol. qPCR was conducted using the high-throughput platform BioMark HD System (Fluidigm). Five $\mu \mathrm{L}$ of Fluidigm sample premix consisted of $1 \mu \mathrm{L}$ of $20 \times$ diluted preamplified cDNA, $0.25 \mu \mathrm{L}$ of $20 \times \mathrm{Gene}$ Expression (GE) sample loading reagent (Fluidigm), $2.5 \mu \mathrm{L}$ of TaqMan universal mastermix II without uracil-N glycoslyase (UNG; Life Technologies), and $1.25 \mu \mathrm{L}$ of RNase/ DNase-free water. Each sample premix was combined with $5 \mu \mathrm{L}$ FAM-MGB assays (Primer Design) at a final concentration of $300 \mathrm{nmol} / \mathrm{L}$ and $2.5 \mu \mathrm{L} 2 \mathrm{x}$ Assay loading reagent (Fluidigm). The reaction volume for a single qPCR reaction was $6.7 \mathrm{~nL}$. Thermal conditions for qPCR were: $95^{\circ} \mathrm{C}$ for 10 minutes, 45 cycles of $95^{\circ} \mathrm{C}$ for 15 seconds, and $60^{\circ} \mathrm{C}$ for 60 seconds. Actin beta (ACTB) and 18S rRNA were used as reference genes selected from a geNorm reference genes selection kit (Primer Design) by Normfinder (GenEx Enterprise).

\section{qPCR data pre-processing}

Data were collected from 2 GE Dynamic Arrays 96.96 (Fluidigm) and pre-processed in GenEx Enterprise software (MultiD). Interplate calibration was conducted and the technical replicates were averaged. Cut-off value for Cq was set at 25. The Cq 25 measured in BioMark system would approximately correspond to $\mathrm{Cq} 35$ at the conventional qPCR cyclers [20]. When more than $12 \%$ of the data were missing for each sample/gene due to a very low expression and low fluorescence signal, the particular sample/gene was removed from the dataset. As a result of this selection MSH4, MSH5 and PMS2L3 genes were excluded from analyses. Data were normalized to reference genes, recalculated to relative quantities with the lowest expression set to 1 , and transformed to $\log 2$ scale.

\section{Promoter $\mathrm{CpG}$ islands methylation profiling Methylation-specific $P C R$}

A prediction of $\mathrm{CpG}$ islands site within the promoter region of MMR genes was carried out by screening with CpG Islands Searcher (http://cpgislands.usc.edu/). Genomic DNA was treated with sodium bisulfite using the Epitect Whole Bisulfitome Kit (Qiagen, Hilden, Germany). Methylation-specific PCR (MSP) analysis of bisulfite-converted DNA was conducted using the Epitect MSP kit (Qiagen, Hilden, Germany), following the producer's protocols. Primers (Sigma-Aldrich; Additional file 1: Table S1a) specific for methylated and unmethylated bisulfite-converted DNA were designed for investigated genes by applying MethPrimer algorithm [21]. To test whether promoter methylation can affect the mRNA expression levels of MMR genes, only those genes which were successfully analyzed for the gene expression were subsequently considered. MSP reactions were performed as previously described by [22].

\section{Methylation-sensitive high resolution melting}

Methylation-sensitive high resolution melting (MS-HRM) was conducted only on those samples that showed positive results in MSP, to validate the observations. Whole genomic DNA was treated with sodium bisulfite using the Epitect Bisulfite Kit (Qiagen, Hilden, Germany) to convert unmethylated cytosines to uracils, following the manufacturer's protocol, as described in [23]. Real-time PCR followed by HRM was carried out in high-performance Eco Real-Time PCR system (Illumina, San Diego, CA, USA). Primer sequences for $M L H 1$ were described earlier [23,24], while for $M L H 3$ primers (Additional file 1: Table S1b) were designed using Methyl Primer Express Software v1.0 (Applied Biosystems, Foster City, CA, USA). The reaction mixture (10 $\mu \mathrm{l}$ final volume) consisted of $10 \mathrm{ng}$ of template DNA, 1× EpiTect HRM Master Mix (Qiagen) and $300 \mathrm{nmol} / \mathrm{l}$ of each primers. PCR was initiated by incubation at $95^{\circ} \mathrm{C}$ for $5 \mathrm{~min}$, followed by 50 cycles at $95^{\circ} \mathrm{C}$ for $10 \mathrm{sec}, 56^{\circ} \mathrm{C}$ for $20 \mathrm{sec}, 72^{\circ} \mathrm{C}$ for $10 \mathrm{sec}$. For each assay, a standard dilution series of EpiTect Control DNAs (Qiagen) was run to assess the quantitative properties and sensitivity of the assay. Fluorescence data were converted into melting peaks by the Eco Software (Illumina, Ver. 3.0.16.0). The cut-off value for aberrant methylation was set to $25 \%$ or higher.

\section{Statistical analyses}

Statistical analyses were conducted by IBM SPSS Statistics 18, GenEx Enterprise and SAS 9.2 software. Expression levels of all studied genes did not follow a normal distribution in the study population, as analyzed by Kolmogorov-Smirnov test. Data were logarithmically transformed and nonparametric tests were used for statistical analyses; for comparison of medians, Mann-Whitney test was applied. Correlations were determined by a Spearmen correlation coefficient. All statistical tests were conducted at a 95\% confidence level. 


\section{Results}

Population characteristics

The detailed patient's characteristics are shown in Table 1 . The study group included 38 men and 15 women with a mean age of $67.0( \pm 10.6)$ years. Twenty six patients had a tumor localized in the colon and 27 in the rectum. Seven patients were diagnosed with pathologic stage I, 27 with stage II, 11 with stage III and 8 with stage IV. All tumors were histologically confirmed as adenocarcinomas. Three patients had tumor of a well-differentiated grade, 43 a moderately differentiated and 7 patients poorly differentiated.

Ten patients with rectal cancer received neoadjuvant therapy before surgery.

\section{MSI status}

Tumor tissue of 6 patients displayed MSI. For all of them, 3 and more loci showed nucleotide expansions and they were therefore considered to be MSI-H. All six patients were diagnosed for colon cancer. No association of MSI status with gender, age, TNM and grade was observed.

Table 1 Patients' characteristics

\begin{tabular}{lc}
\hline & N (\%) \\
\hline Gender & $38(71.7)$ \\
Male & $15(28.3)$ \\
Female & \\
Age at diagnosis (years) & $67.0 \pm 10.6$ \\
Mean \pm SD & \\
Diagnosis & $26(49.1)$ \\
Colon cancer & $27(50.9)$ \\
Rectal cancer & \\
pTNM status & $7(13.2)$ \\
I & $27(50.9)$ \\
II & $11(20.8)$ \\
III & $8(15.1)$ \\
IV & \\
Grade & $3(5.7)$ \\
Well-differentiated & $43(81.1)$ \\
Moderately differentiated & $7(13.2)$ \\
Poorly differentiated & \\
MSI status & $47(88.7)$ \\
MSS & $6(11.3)$ \\
MSI-H & \\
MSI status in colon cancer & $5(83.3)$ \\
Distal colon & $16.7)$ \\
\hline
\end{tabular}

\section{Expression of MMR genes}

Expression levels of 8 MMR genes were successfully analyzed (Figure 1, Additional file 1: Table S2). Three other MMR genes (MSH4, MSH5 and PMS2L3) were excluded from final analyses due to a very low expression and low fluorescence signal.

Overall, only EXO1 was differentially expressed in our study group: significantly higher mRNA levels were observed in tumor tissues when compared with adjacent mucosal tissue (1.16-fold; $\mathrm{P}=0.048$; Figure 1 ).

After stratifying patients according to the tumor localization, a different pattern for colon and for rectal carcinomas was observed. Specifically, significantly higher expression levels of MSH3 gene were observed in colon tumors when compared to adjacent mucosal tissue (1.18 fold change, $\mathrm{P}=0.02$; Additional file 1: Table $\mathrm{S} 3 \mathrm{~b})$. No differences in gene expression were observed in rectal tumors when compared to adjacent mucosal tissues.

Interestingly, when expression levels of only tumor tissues with different localization were compared, tumor localized in colon showed significantly increased levels of almost all analyzed MMR genes, namely $M S H 2(1.68, \mathrm{P}<$ 0.0001), MSH3 (1.27, $\mathrm{P}=0.001)$, MSH6 (1.43, $\mathrm{P}=0.004)$, PMS2 (1.16, $\mathrm{P}=0.005)$ and EXO1 (1.30 fold change, $\mathrm{P}=$ 0.02) (Figure 2; Additional file 1: Table S3a). Although less robust, the same tendency was also observed in the adjacent mucosal tissue for MSH2 (1.65 fold change, $\mathrm{P}=0.02$ ) and PMS2 $(1.18, \mathrm{P}=0.03)$ genes. Further stratification for left and right colon did not show any differences (data not shown).

The expression pattern of investigated MMR genes was irrespective of other clinical features (pTNM staging and tumor differentiation). The only exception was for PMS2 gene in colon tumors, where patients with the pTNM stage I + II had significantly lower expression levels than those with pTNM III + IV $(-1.13, \mathrm{P}=0.01$; data not shown). No difference was observed when patients were stratified for any of the considered demographic factors (e.g. age, sex).

Ten patients with rectal cancer (18.9\%) received neoadjuvant therapy before surgery. However, none of the analyzed genes differed in the expression levels among rectal cancer patients irrespectively of the neoadjuvant therapy.

\section{Relationships of expression levels among different MMR genes}

MMR genes positively correlated between each other in both tumor and adjacent mucosal tissues (Tables 2 and 3). The most pronounced significant correlations in tumors were observed between $M L H 3$ and PMS1 or PMS2 $(\mathrm{R}=$ 0.822 and $\mathrm{R}=0.903, \mathrm{P}<0.0001$ for both); between $M S H 2$ and MSH6 ( $\mathrm{R}=0.854, \mathrm{P}<0.0001)$, and both PMS1 and PMS2 $(\mathrm{R}=0.835, \mathrm{P}<0.0001)$ (Table 2). 


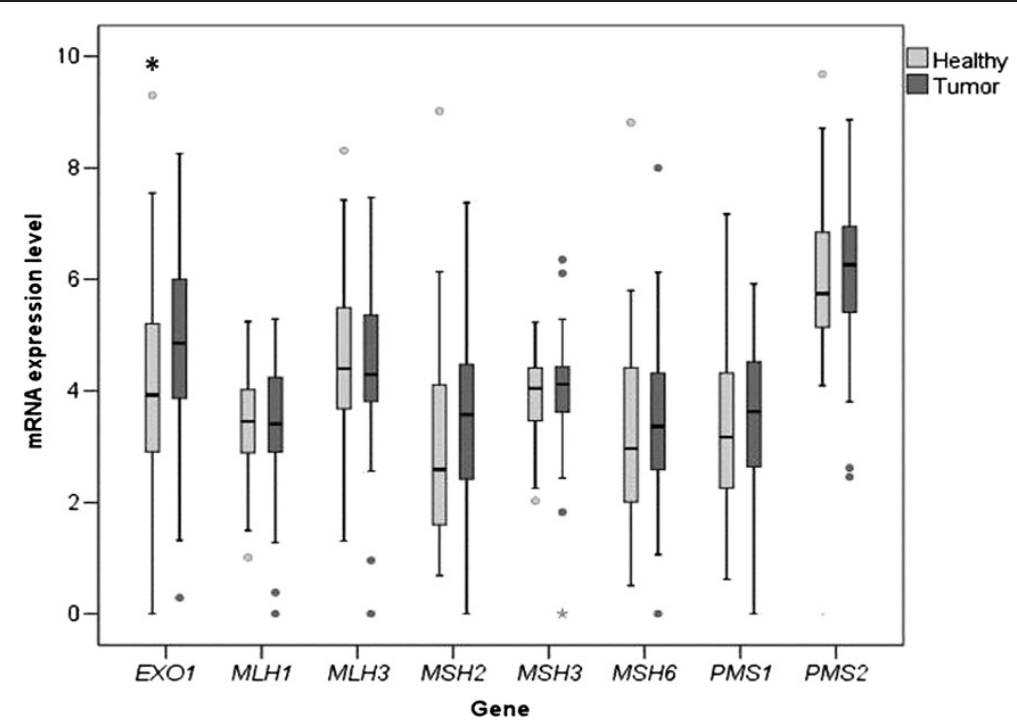

Figure 1 mRNA expression levels of MMR genes in tumor and adjacent mucosal tissues in the study subjects, expressed as quantities relative to the lowest detected expression assigned as value 1 .

Similarly to cancer tissues, in adjacent mucosal tissues, MLH3 correlated with PMS1 and PMS2 $(\mathrm{R}=0.887$ and $\mathrm{R}=$ 0.931, $\mathrm{P}<0.000$, respectively), but, additionally, $M L H 3$ also correlated with MSH6 $(\mathrm{R}=0.857, \mathrm{P}<0.0001)$. In addition, MSH2 again correlated with MSH6 $(\mathrm{R}=0.880, \mathrm{P}<0.0001)$ and PMS1 and PMS2 $(\mathrm{R}=0.855, \mathrm{P}<0.0001)$. Concerning the EXO1, in adjacent mucosal tissue the gene strongly correlated with $M L H 3, M S H 6$ and $P M S 1(\mathrm{R}=0.849, \mathrm{R}=0.849$, and $\mathrm{R}=0.814, \mathrm{P}<0.0001$ for all) (Table 3 ).

\section{Promoter methylation of MMR genes}

The promoter methylation status was analyzed only in those genes whose expression analyses were successfully conducted. Therefore, methylation levels of promoter regions of EXO1, MLH1, MLH3, PMS1, PMS2, MSH2, $M S H 3$, and MSH6 genes were evaluated in DNA from tumor and adjacent mucosal tissues of 53 CRC patients. Methylation of promoter region was detected only in MLH1 (Additional file 2: Figure S1). For this gene, a

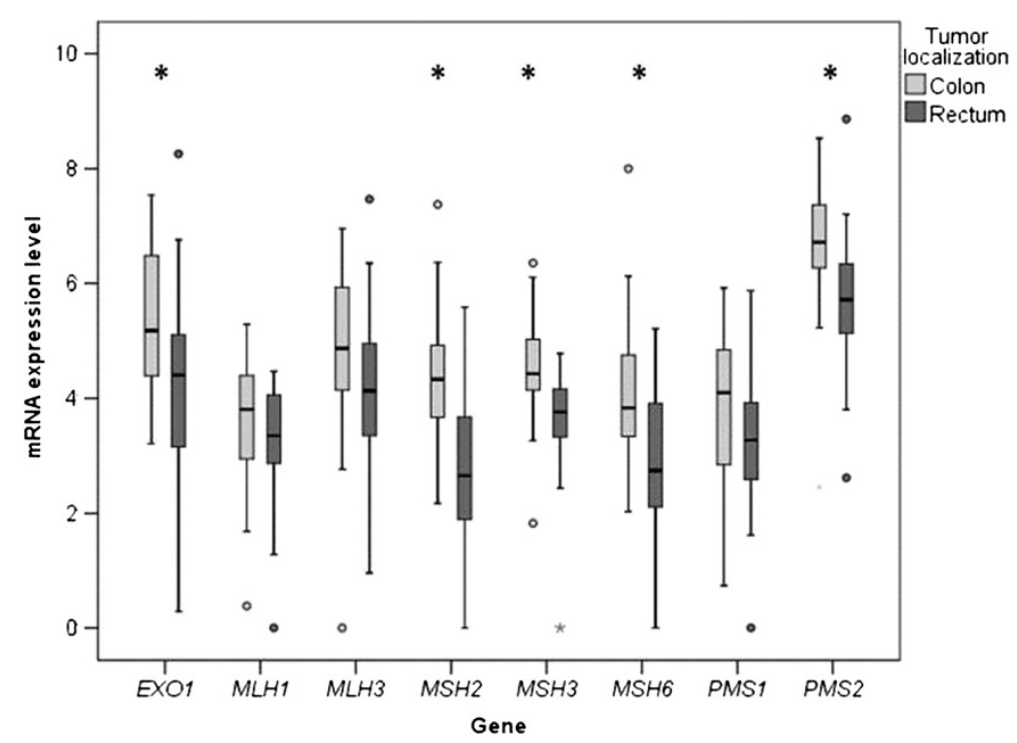

Figure 2 mRNA expression levels of MMR genes in colon and rectum tumors, expressed as quantities relative to the lowest detected expression assigned as value 1 . 
Table 2 Correlations between mismatch repair genes in tumor tissues

\begin{tabular}{|c|c|c|c|c|c|c|c|c|}
\hline Gene & Exo1 & Mlh1 & Mlh3 & Msh2 & Msh3 & Msh6 & Pms1 & Pms2 \\
\hline Exo1 & 1 & & & & & & & \\
\hline Mlh1 & $0.244(0.115)$ & 1 & & & & & & \\
\hline Mlh3 & $0.721(\mathbf{0 . 0 0 0 )}$ & $0.395(\mathbf{0 . 0 0 9})$ & 1 & & & & & \\
\hline Msh2 & $0.577(\boldsymbol{0 . 0 0 0})$ & $0.285(0.064)$ & $0.601(\mathbf{0 . 0 0 0 )}$ & 1 & & & & \\
\hline Msh3 & $0.125(0.423)$ & $0.495(\mathbf{0 . 0 0 1})$ & $0.268(0.082)$ & $0.478(\mathbf{0 . 0 0 1})$ & 1 & & & \\
\hline Msh6 & $0.648(\mathbf{0 . 0 0 0})$ & $0.177(0.257)$ & $0.695(\mathbf{0 . 0 0 0 )}$ & $0.854(\mathbf{0 . 0 0 0})$ & $0.247(0.110)$ & 1 & & \\
\hline Pms1 & $0.711(\mathbf{0 . 0 0 0})$ & $0.368(\mathbf{0 . 0 1 5})$ & $0.822(\mathbf{0 . 0 0 0})$ & $0.593(\mathbf{0 . 0 0 0})$ & $0.191(0.220)$ & $0.670(\mathbf{0 . 0 0 0})$ & 1 & \\
\hline Pms2 & $0.783(\boldsymbol{0 . 0 0 0})$ & $0.381(\mathbf{0 . 0 1 2})$ & $0.903(\boldsymbol{0 . 0 0 0})$ & $0.745(\mathbf{0 . 0 0 0})$ & $0.342(\mathbf{0 . 0 2 5})$ & $0.784(\boldsymbol{0 . 0 0 0})$ & $0.835(\mathbf{0 . 0 0 0})$ & 1 \\
\hline
\end{tabular}

$\mathrm{R}$ and $\mathrm{P}$ value (in brackets), Significant differences are in bold, differences significant after Dunn-Bonferroni correction $(\mathrm{P}<0.0032)$ are in italics.

fragment of 100 bp length containing 8 CpG sites was analyzed. Five tumors and two samples from adjacent mucosal tissues exhibited methylated $M L H 1$ promoter region. In patients, where normal tissues presented $M L H 1$ promoter methylation, tumor tissue also exhibited promoter methylation.

The investigated promoter region resulted methylated in MSI-H colon tumors only $(\mathrm{p}<0.00001)$.

We did not observe any statistical significant variation in mRNA expression levels of MLH1 gene in the patients with promoter methylation when compared to patients without promoter methylation.

\section{Discussion}

Genetic and epigenetic alterations underlie the pathogenesis of cancer. In particular, the disruption of epigenetic mechanisms leads to abnormal development of cells and is involved in malignant transformation [25]. Variations in DNA methylation are important epigenetic modifications which may affect gene expression by modifying the DNA structure without altering the native nucleotide sequence.

In the present study, we have analyzed the mRNA expression of MMR genes and their promoter methylation in CRC tissues in patients from the Czech Republic, a country that has the second highest CRC incidence and mortality among 38 European countries [1]. With the exception of $M L H 1$ and $M S H 2$ genes, the methylation status of the other MMR genes was globally less studied or even never previously analyzed.

In our study, we observed the promoter methylation of $M L H 1$ gene only. Notably, this modification was observed in MSI-H colon tumors only, as it is generally observed in CRC [14]. The incidence of $M L H 1$ promoter methylation observed in our study is in concordance with another Czech study of Vasovcak et al. [26], where mutational profiles of CRC high risk genes together with methylation of $M L H 1$ gene were analyzed. Similarly to the work of Vasovcak et al. [26], any MLH1 promoter methylation was not detected in rectal tumors. Rare MLH1 promoter methylation in rectal cancers was described also in the study of Samowitz et al. [27], but it was accompanied by high degree of MMR protein deficiency, possibly due to the inclusion of Lynch associated tumors. The reason for the differential $M L H 1$ promoter methylation and tumor localization is still unknown and can be caused by dietary habits, different environment (e.g. varying $\mathrm{pH}$ ) in different parts of the colon, or by the combination of both aspects [26] or by other factors which could affect the presence of promoter methylation, like presence of bacterial flora [28]. In our study, the presence of promoter methylation of $M L H 1$ gene was also not related to the mRNA levels. This lack of association could be due to the small size of the population. An inverse correlation to $M L H 1$ expression was observed in a previous study of Oster et al. [24] and may

Table 3 Correlations between mismatch repair genes in adjacent mucosal tissues

\begin{tabular}{|c|c|c|c|c|c|c|c|c|}
\hline Gene & Exo1 & Mlh1 & Mlh3 & Msh2 & Msh3 & Msh6 & Pms1 & Pms2 \\
\hline Exo1 & 1 & & & & & & & \\
\hline Mlh1 & $0.323(\mathbf{0 . 0 3 5})$ & 1 & & & & & & \\
\hline Mlh3 & $0.849(\mathbf{0 . 0 0 0})$ & $0.362(\mathbf{0 . 0 1 7})$ & 1 & & & & & \\
\hline Msh2 & $0.758(\mathbf{0 . 0 0 0})$ & $0.230(0.139)$ & $0.715(\mathbf{0 . 0 0 0})$ & 1 & & & & \\
\hline Msh3 & $0.046(0.771)$ & $0.511(\mathbf{0 . 0 0 0})$ & $0.166(0.289)$ & $0.281(0.068)$ & 1 & & & \\
\hline Msh6 & $0.849(\mathbf{0 . 0 0 0})$ & $0.230(0.192)$ & $0.857(\boldsymbol{0 . 0 0 0})$ & $0.880(\boldsymbol{0 . 0 0 0})$ & $0.054(0.731)$ & 1 & & \\
\hline Pms1 & $0.814(\mathbf{0 . 0 0 0})$ & $0.399(\mathbf{0 . 0 0 8})$ & $0.887(\mathbf{0 . 0 0 0})$ & $0.630(\boldsymbol{0 . 0 0 0})$ & $0.100(0.525)$ & $0.769(\mathbf{0 . 0 0 0})$ & 1 & \\
\hline Pms2 & $0.793(\mathbf{0 . 0 0 0})$ & $0.367(\mathbf{0 . 0 1 6})$ & $0.931(\mathbf{0 . 0 0 0})$ & $0.658(\mathbf{0 . 0 0 0})$ & $0.135(0.390)$ & $0.782(\mathbf{0 . 0 0 0})$ & $0.855(\mathbf{0 . 0 0 0 )}$ & 1 \\
\hline
\end{tabular}

$\mathrm{R}$ and $\mathrm{P}$ value (in brackets), Significant differences are in bold, differences significant after Dunn-Bonferroni correction $(\mathrm{P}<0.0032)$ are in italics. 
have different explanation. Methylation of $M L H 1$ gene might be explained by the fact that only few CpG sites were interrogated, and the interrogated sites may not be the sites involved in regulation of the gene. In addition, the presence of alternative transcription start sites may also be involved. Recently Jones [29] summarized that genes silenced by Polycomb complexes are much more likely than other genes to become methylated in cancer and thus a silent state could even precede methylation. Thus, the evidence regarding the timing of DNA methylation could be consistent with the idea that methylation adds an additional level of stability to epigenetic states.

In patients where the tumor and normal tissues presented MLH1 promoter methylation, blood samples were also analyzed to confirm potential germline hypermethylation. However, in our study, we did not observe any $M L H 1$ promoter methylation in the DNA from blood (data not shown). This result pointed to somatic origin of $M L H 1$ promoter methylation in our study.

Although rather small (1.16-fold), we also observed different expression levels for EXO1 gene when compared tumor and adjacent mucosal tissues. Higher expression levels for EXO1 in tumor tissues are in agreement with the study of Ioana et al. [30]. Although, data in that study were normalized to a different reference gene, GAPDH, and the investigated population was also smaller than ours. Recently, Caradec et al. [31] suggested not to use GAPDH as a reference gene for normalization in CRC experiments, since it appears to be among the most variable. Other authors showed that GAPDH expression varies according to oxygen tension and hypoxia, critical factors in cancer development, especially in CRC [32]. On the other hand, Ide et al. [33] observed a lower mRNA level of MMR genes in tumor samples as compared with the normal tissue. In our study, MSH3 gene had significantly higher expression levels in colon tumors when compared to adjacent mucosa. Tentori et al. [34] observed that defective expression of the protein MSH3 is frequently detected in colon cancer. Higher expression levels were found in tumors of the colon when compared to those in the rectum. These differences were more pronounced in EXO1, MSH2, MSH3, MSH6, and PMS2 genes. The same tendency was observed in adjacent mucosa for $M S H 2$ and PMS2 genes. Our results may suggest different mechanisms in the genesis of colon and rectal cancers as it was already postulated by [35]. The reason for higher mRNA levels of MMR genes in colon could be actually due to the fact that stools are kept in the colon for a longer time than in the rectum. In this way, colon is more exposed to various carcinogens from the food, and thus needs more protection against the carcinogenic events. Higher expression levels of DNA repair genes could be one of these mechanisms of protection. As tumor localization was the major factor influencing gene expression, location- specific analysis may identify location-associated pathways and enhance the accuracy of class prediction.

In the present study, we have also observed a strong relationship between between EXO1 expression and those of genes involved in the MutS $\alpha$ heterodimer (MSH2-MSH6). Previously, Jiricny [36] also noticed that decreased activity of EXO1 is accompanied with the low concentrations of genes involving in the MutS $\alpha$ heterodimer.

We observed a strong correlation between expressions of $\mathrm{MSH} 2$ and $\mathrm{MSH} 6$ genes. Vageli et al. [37] recently demonstrated that reduction of MSH6 mRNA levels is a frequent event in bladder tumorigenesis and reflects a common mechanism of suppression with $\mathrm{MSH} 2$. Another MMR heterodimer, MutL $\alpha$, consisting of $M L H 1$ and PMS2, positively correlated, but the strength of such correlation was considerably lower than that for the MutS $\alpha$ heterodimer. Interestingly, the strongest correlations were observed between MLH3 and PMS1 and PMS2. This is the first time that a correlation between above genes is reported. Previous observations indicated that PMS2 gene is required for the correction of singlebase mismatches, and PMS 2 and MLH3 contribute both to the correction of insertion-deletion loops resulting from DNA replication, DNA damage or from recombination events between non-identical sequences during meiosis [38]. The role of PMS1 in MMR still awaits further clarification, but it is assumed that coordinates the downstream processes after mismatch recognition by MutS $\alpha$ heterodimer together with $M L H 1$ [39].

DNA repair pathways are a part of a multistep, multifactorial process to remove the damaged DNA sequence and to resynthesize particular part of the DNA strand. Thus, interplay exerted by multiple genes is crucial and more informative for identifying genes responsible for human cancer. Analyzing the difference in expression, individual variability, and co-expression in our study has provided an initial characterization of the MMR pathway and can help in further understanding of the cellular DNA repair system in human CRC.

A lack of association between methylation in MMR genes (representing rather low-frequency events) and their corresponding expressions could be due to the small size of the population. Above aspect emerges therefore as a main limitation of the present study.

\section{Conclusions}

In summary, our combined genetic and epigenetic analysis confirmed some previous data from other studies on CRC patients, but also provided novel findings. First, a strong correlation was observed either between $M L H 3$ and PMS1 or PMS2. Second, although we did not confirm the expected traits of deregulation of MMR genes in sporadic CRC in patients recruited in the Czech Republic, we have found interesting and strong differences 
in expression of almost all MMR genes when colon and rectal tumors were compared. This finding might point to the distinct genesis of both neoplasia. Outcomes of the present study will require further validation with functional assays, particularly in tumors and in larger population study.

\section{Additional file}

Additional file 1: Table S1a. Primer sequences for each MMR gene for the amplification of $\mathrm{M}$ (methylated) and $U$ (unmethylated) template DNA. Table S1b: Primers for MS-HRM. Table S2. mRNA expression levels of MMR genes in tumor and adjacent mucosal tissues in the study subjects. Table S3a. mRNA expression levels of MMR genes after stratification for tumor localization. Table S3b. mRNA expression levels of MMR genes in colon cancer.

Additional file 2: Figure S1. MLH1 promoter methylation presented in adjacent mucosal tissue in Patient 2 by MSP. ( $\mathrm{H}=$ adjacent mucosal tissue, $\mathrm{T}=$ tumor tissue; $\mathrm{U}=$ amplified sequence with primers complementary to bisulfate converted unmethylated DNA sequence; $\mathrm{M}=$ amplified sequence with primers complementary to bisulfate converted methylated DNA seguence; $\mathrm{NC}=$ negative control; $\mathrm{PC}=$ positive control).

\section{Abbreviations}

ACTB: Actin beta; CDNA: Complementary DNA; CIMP: Cytosine phosphate guanine island methylator phenotype; CIN: Chromosomal instability; CpG: Cytosine polyguanine; CRC: Colorectal cancer; MMR: Mismatch repair; MSI: Microsatellite instability; MSI-H: MSI high; MSI-L: MSI low; QPCR: Quantitative PCR; TNM: Tumor-node-metastasis; UICC: Union for International Cancer Control; UNG: Uracil-N glycoslyase.

\section{Competing interests}

The authors declare that they have no competing interests.

\begin{abstract}
Authors' contributions
VPV was responsible for drafting the manuscript, methylation specific PCR and participated in the whole design of the study. SJ performed the statistical analysis and interpretation of data. KV carried out the GPCR analysis and preamplification analysis. BL was supplier of samples. LL carried out the QPCR analysis and preamplification analysis. PP was responsible for verification of methylation data by HRM. RA assisted in verification of methylation data by HRM. SL was supplier of samples. PB revised the manuscript critically for important intellectual content. NA helped to draft the manuscript. PV, department chair, coordinated whole research and helped to draft the manuscript. All authors read and approved the final manuscript.
\end{abstract}

\section{Acknowledgements}

The study was supported by grant GA CR P304/11/P715 and Prvouk-P27/ LF1/1 from Ministry of Education, Youth and Sport, Czech Republic (First Medical Faculty, Charles University, Prague, Czech Republic as a recipient) and by AV0Z50520701 and GAAV IAA500200917.

\section{Author details}

${ }^{1}$ Institute of Experimental Medicine Academy of Sciences of the Czech Republic, Prague, Czech Republic. 'Institute of Biology and Medical Genetics, First Faculty of Medicine Charles University, Prague, Czech Republic. ${ }^{3}$ Institute of Biotechnology, Academy of Sciences of the Czech Republic, Prague, Czech Republic. ${ }^{4}$ Faculty of Science, Charles University, Albertov 6, Prague, Czech Republic. ${ }^{5}$ Human Genetics Foundation, Turin, Italy.

Received: 30 July 2013 Accepted: 28 January 2014

Published: 31 January 2014

\section{References}

1. Jemal A, Bray F, Center MM, Ferlay J, Ward E, Forman D: Global cancer statistics. CA Cancer J Clin 2011, 61(2):69-90.
2. Naccarati A, Pardini B, Landi S, Landi D, Slyskova J, Novotny J, Levy M, Polakova V, Lipska L, Vodicka P: Polymorphisms in miRNA-binding sites of nucleotide excision repair genes and colorectal cancer risk. Carcinogenesis 2012, 33(7):1346-1351.

3. Center M, Jemal A, Ward E: International trends in colorectal cancer incidence rates. Cancer Epidemiol Biomarkers Prev 2009, 18(6):1688-1694.

4. Center M, Jemal A, Smith R, Ward E: Worldwide variations in colorectal cancer. CA Cancer J Clin 2009, 59(6):366-378.

5. Theodoratou E, Montazeri Z, Hawken S, Allum G, Gong J, Tait V, Kirac I, Tazari M, Farrington S, Demarsh A, et al: Systematic meta-analyses and field synopsis of genetic association studies in colorectal cancer. J Natl Cancer Inst 2012, 104(19):1433-1457.

6. Burgart L: Testing for defective DNA mismatch repair in colorectal carcinoma: a practical guide. Arch Pathol Lab Med 2005, 129(11):1385-1389.

7. Arends M: Pathways of colorectal carcinogenesis. Appl Immunohistochem Mol Morphol 2013, 21(2):97-102.

8. Curtin K, Slattery M, Samowitz W: CpG island methylation in colorectal cancer: past, present and future. Pathol Res Int 2011, 2011:8. Article ID 902674.

9. Venkatachalam R, Ligtenberg M, Hoogerbrugge N, de Bruijn D, Kuiper R, Geurts van Kessel A: The epigenetics of (hereditary) colorectal cancer. Cancer Genet Cytogenet 2010, 203(1):1-6.

10. English D, Young J, Simpson J, Jenkins M, Southey M, Walsh M, Buchanan D, Barker M, Haydon A, Royce S, et al: Ethnicity and risk for colorectal cancers showing somatic BRAF V600E mutation or CpG island methylator phenotype. Cancer Epidemiol Biomarkers Prev 2008, 17(7):1774-1780.

11. Nosho K, Irahara N, Shima K, Kure S, Kirkner G, Schernhammer E, Hazra A, Hunter D, Quackenbush J, Spiegelman D, et al: Comprehensive biostatistical analysis of $\mathrm{CpG}$ island methylator phenotype in colorectal cancer using a large population-based sample. PLoS One 2008, 3(11):1-12.

12. Slattery M, Curtin K, Wolff R, Boucher K, Sweeney C, Edwards S, Caan B, Samowitz W: A comparison of colon and rectal somatic DNA alterations. Dis Colon Rectum 2009, 52(7):1304-1311.

13. Shen L, Toyota M, Kondo Y, Lin E, Zhang L, Guo Y, Hernandez N, Chen X, Ahmed $S$, Konishi $K$, et al: Integrated genetic and epigenetic analysis identifies three different subclasses of colon cancer. Proc Natl Acad Sci U S A 2007, 104(47):18654-18659.

14. Sinicrope FA, Foster NR, Thibodeau SN, Marsoni S, Monges G, Labianca R, Kim GP, Yothers G, Allegra C, Moore MJ, et al: DNA mismatch repair status and colon cancer recurrence and survival in clinical trials of 5-fluorouracil-based adjuvant therapy. J Natl Cancer Inst 2011, 103(11):863-875.

15. van Roon E, van Puijenbroek M, Middeldorp A, van Eijk R, de Meijer E, Erasmus D, Wouters K, van Engeland M, Oosting J, Hes F, et al: Early onset MSI-H colon cancer with MLH1 promoter methylation, is there a genetic predisposition? BMC Cancer 2010, 10:1-10.

16. Poynter J, Haile R, Siegmund K, Campbell P, Figueiredo J, Limburg P, Young J, Le Marchand L, Potter J, Cotterchio M, et al: Associations between smoking, alcohol consumption, and colorectal cancer, overall and by tumor microsatellite instability status. Cancer Epidemiol Biomarkers Prev 2009, 18(10):2745-2750.

17. Worthley DL, Whitehall VL, Spring K, Leggett BA: Colorectal carcinogenesis: road maps to cancer. World J Gastroenterol 2007, 13(28):3784-3791.

18. Goel A, Xicola R, Nguyen T, Doyle B, Sohn V, Bandipalliam P, Rozek L, Reyes J, Cordero C, Balaguer F, et al: Aberrant DNA methylation in hereditary nonpolyposis colorectal cancer without mismatch repair deficiency. Gastroenterology 2010, 138(5):1854-1862.

19. Berg KD, Glaser $C L$, Thompson RE, Hamilton SR, Griffin CA, Eshleman JR: Detection of microsatellite instability by fluorescence multiplex polymerase chain reaction. J Mol Diagn 2000, 2(1):20-28.

20. Spurgeon SL, Jones RC, Ramakrishnan R: High throughput gene expression measurement with real time PCR in a microfluidic dynamic array. PLoS One 2008, 3(2):e1662.

21. Li LC, Dahiya R: MethPrimer: designing primers for methylation PCRs. Bioinformatics 2002, 18(11):1427-1431.

22. Petko Z, Ghiassi M, Shuber A, Gorham J, Smalley W, Washington MK, Schultenover S, Gautam S, Markowitz SD, Grady WM: Aberrantly methylated CDKN2A, MGMT, and MLH1 in colon polyps and in fecal DNA from patients with colorectal polyps. Clin Cancer Res 2005, 11(3):1203-1209.

23. Slyskova J, Korenkova V, Collins AR, Prochazka P, Vodickova L, Svec J, Lipska L, Levy M, Schneiderova M, Liska V, et al: Functional, genetic, and 
epigenetic aspects of base and nucleotide excision repair in colorectal carcinomas. Clin Cancer Res 2012, 18(21):5878-5887.

24. Oster B, Thorsen K, Lamy P, Wojdacz TK, Hansen LL, Birkenkamp-Demtroder K, Sorensen KD, Laurberg S, Orntoft TF, Andersen CL: Identification and validation of highly frequent $\mathrm{CpG}$ island hypermethylation in colorectal adenomas and carcinomas. Int J Cancer 2011, 129(12):2855-2866.

25. Tsai HC, Baylin SB: Cancer epigenetics: linking basic biology to clinical medicine. Cell Res 2011, 21(3):502-517.

26. Vasovcak P, Pavlikova K, Sedlacek Z, Skapa P, Kouda M, Hoch J, Krepelova A: Molecular genetic analysis of 103 sporadic colorectal tumours in Czech patients. PLoS One 2011, 6(8):e24114.

27. Samowitz WS, Curtin K, Wolff RK, Tripp SR, Caan BJ, Slattery ML: Microsatellite instability and survival in rectal cancer. Cancer Causes Control 2009, 20(9):1763-1768.

28. Takahashi K, Sugi Y, Nakano K, Tsuda M, Kurihara K, Hosono A, Kaminogawa S: Epigenetic control of the host gene by commensal bacteria in large intestinal epithelial cells. J Biol Chem 2011, 286(41):35755-35762.

29. Jones PA: Functions of DNA methylation: islands, start sites, gene bodies and beyond. Nat Rev Genet 2012, 13(7):484-492.

30. Ioana M, Angelescu C, Burada F, Mixich F, Riza A, Dumitrescu T, Alexandru D, Ciurea T, Cruce M, Saftoiu A: MMR gene expression pattern in sporadic colorectal cancer. J Gastrointestin Liver Dis 2010, 19(2):155-159.

31. Caradec J, Sirab N, Revaud D, Keumeugni C, Loric S: Is GAPDH a relevant housekeeping gene for normalisation in colorectal cancer experiments? Br J Cancer 2010, 103(9):1475-1476.

32. Baba Y, Huttenhower C, Nosho K, Tanaka N, Shima K, Hazra A Schernhammer ES, Hunter DJ, Giovannucci EL, Fuchs CS, et al: Epigenomic diversity of colorectal cancer indicated by LINE-1 methylation in a database of 869 tumors. Mol Cancer 2010, 9:125.

33. Ide T, Kitajima Y, Ohtaka K, Mitsuno M, Nakafusa Y, Miyazaki K: Expression of the $\mathrm{hMLH} 1$ gene is a possible predictor for the clinical response to 5 -fluorouracil after a surgical resection in colorectal cancer. Oncol Rep 2008, 19(6):1571-1576.

34. Tentori L, Muzi A, Dorio AS, Dolci S, Campolo F, Vernole P, Lacal PM, Praz F, Graziani G: MSH3 expression does not influence the sensitivity of colon cancer HCT116 cell line to oxaliplatin and poly(ADP-ribose) polymerase (PARP) inhibitor as monotherapy or in combination. Cancer Chemother Pharmacol 2013, 72(1):117-125.

35. Kapiteijn E, Liefers GJ, Los LC, Kranenbarg EK, Hermans J, Tollenaar RA, Moriya $\mathrm{Y}$, van de Velde $\mathrm{CJ}$, van Krieken JH: Mechanisms of oncogenesis in colon versus rectal cancer. J Pathol 2001, 195(2):171-178.

36. Jiricny J: MutLalpha: at the cutting edge of mismatch repair. Cell 2006, 126(2):239-241.

37. Vageli DP, Giannopoulos S, Doukas SG, Kalaitzis C, Giannakopoulos S, Giatromanolaki A, Koukoulis GK, Touloupidis S: Mismatch repair hMSH2, hMLH1, hMSH6 and hPMS2 mRNA expression profiles in precancerous and cancerous urothelium. Oncol Lett 2013, 5(1):283-294.

38. Peltomaki P: Role of DNA mismatch repair defects in the pathogenesis of human cancer. J Clin Oncol 2003, 21(6):1174-1179.

39. Martin-Lopez JV, Fishel R: The mechanism of mismatch repair and the functional analysis of mismatch repair defects in Lynch syndrome. Fam Cancer 2013, 12(2):159-168.

doi:10.1186/1471-2350-15-17

Cite this article as: Vymetalkova et al:: Molecular characteristics of mismatch repair genes in sporadic colorectal tumors in Czech patients. BMC Medical Genetics 2014 15:17.

\section{Submit your next manuscript to BioMed Central and take full advantage of:}

- Convenient online submission

- Thorough peer review

- No space constraints or color figure charges

- Immediate publication on acceptance

- Inclusion in PubMed, CAS, Scopus and Google Scholar

- Research which is freely available for redistribution 